\title{
Engaging Stakeholders for Collaborative Decision Making in Humanitarian Logistics Using System Dynamics
}

\author{
${ }^{1}$ School of Public Policy and Administration, Xi' an Jiaotong University, Xi'an, Shaanxi, P.R. China \\ ${ }^{2}$ School of Public Administration, University of Central Florida, Orlando, FL, USA, E-mail: kapucu@ucf.edu
}

\begin{abstract}
:
Participatory System Dynamics modeling is presented as a methodology to engage stakeholders in collaborative decision making in scenarios involving humanitarian logistics. Using the System Dynamics (SD) model, we simulated different scenarios, the results of which yielded factors that influence performance of humanitarian logistics. Once these were identified and discussed, different options on performance improvement were tested. This approach showed that the SD model can facilitate system thinking for stakeholders and form shared mental models critical to reaching consensus-based decisions in humanitarian logistics situations.
\end{abstract}

Keywords: collaborative decision making, humanitarian logistics, participatory modeling, system dynamics DOI: 10.1515/jhsem-2018-0061

\section{Introduction}

We've observed significant increases in disasters around the globe, such as earthquakes, hurricanes/typhoons, and floods (Ergonul 2005; Li and Tang 2008; World Bank 2015). During and after disasters, the need to deliver goods for relief operations to affected areas (humanitarian logistics) is very important (Zhao and Cao 2015), but these operations are challenged by inaccurate, limited, and inaccessible information (Sheu 2007). In addition, humanitarian logistics often have to be carried out in an environment with destabilized infrastructures ranging from a lack of power and supplies to limited transportation infrastructure (Long and Wood 1995). This makes improving the efficiency and effectiveness of humanitarian logistics operations critical and performance issues deserving of considerable attention (Najjar, Dahabiyeh, and Nawayseh 2018).

Various factors influence the performance of humanitarian logistics in the context of disasters. Operations become difficult due to the lack of information, nonlinear conditions, and the need for timely and flexible decision making (Holguín-Veras et al. 2014, 87). As such, humanitarian logistics systems form a "temporary configuration of otherwise disparate resources" (Smith and Dowell 2000)and various stakeholders - such as government agencies, private firms, nonprofit organizations, and individuals - come together to provide urgent humanitarian relief goods and services (Kaynak and Tuğer 2014). Collaboration and collective action can be very challenging (Long and Wood 1995) given different cultures and traditions. Lack of a coordinated decisionmaking process often leads to substantial confusion, ineffective response, and recovery (Murray 2005).

These challenges highlight the importance of stakeholder engagement in collaborative decision-making (Blackstock, Kelly, and Horsey 2007). Stakeholder engagement must support democratic principles, promote learning, integrate information/knowledge, and add legitimacy to the process to move toward improved humanitarian logistics initiatives (Bosch et al. 2013; Kapucu and Garayev 2011; Tatham and Christopher 2014).

This study builds on and contributes to earlier studies on humanitarian logistics (Garrido, Lamas, and Pino 2015; Jeong, Hong, and Xie 2014; Wang, Song, and Shi 2015) by presenting a SD-based model (Forrester 1961; Ghaffarzadegan, Lyneis, and Richardson 2011) which introduces participatory modeling as a methodology by which to engage stakeholders (Stave 2010). This model can be used to help describe the cause-and-effect relationships and derivations of data that form shared mental models (Kapucu and Garayev 2011).

Methodologically, SD model building and simulations are integral to the decision-making process. Simulation models also enable analyzing critical humanitarian logistics issues in a safe environment (Berariu et al. 2016). The model fosters understanding of how humanitarian logistics operate in different scenarios.

Naim Kapucu is the corresponding author.

(c) 2020 Walter de Gruyter $\mathrm{GmbH}$, Berlin/Boston.

This content is free. 
SD models facilitating stakeholder engagement are presented in the paper. By describing the assumptions and derivation of data, we aim to offer stakeholders the opportunities to establish the model through a participatory process. This computer-aided simulation approach enables effective, efficient, collaborative decision making to improve humanitarian logistics performance.

\section{Literature Review and Background}

In the section titled, Collaborative Decision Making on Humanitarian Logistics, we highlight the importance of collaborative decision making. In the section titled, Decision Support for Disaster Operations Using SD, we discuss the application of SD in disaster operations and confirm that the SD-based model can be used to support collaborative decision making for disaster operations.

\section{Collaborative Decision Making on Humanitarian Logistics}

It is crucial for participating organizations to achieve smooth and effective decision making in disaster management (Kapucu and Garayev 2011). Issues have been addressed extensively at individual and organizational levels (Bigley and Roberts 2001; Flin 2001; Flueler 2006; Useem, Cook, and Sutton 2005), but due to severity of situations, such as lack of information, uncertainties, and involvement of several organizations/stakeholders (Buchanan and O'Connell 2006; Cosgrave 1996; Flueler 2006; Johnston, Driskell, and Salas 1997), decision making in disaster management remains very complex and challenging (Bigley and Roberts 2001; Buchanan and O'Connell 2006; Cozzolino 2010; Ortuño et al. 2013; Sellnow, Seeger, and Ulmer 2002). Another challenge lies in the need for the continuous development of collaborative decision-making skills (Thayaparan et al. 2015).

In the context of disasters, humanitarian logistics sets out to mobilize resources, skills and knowledge to help vulnerable populations (Van Wassenhove 2006, 476). Recently, several decision support systems and technologies, including simulation techniques and vehicle routing algorithms (Barbarosoğlu, Özdamar, and Cevik 2002; Hwang 1999; Ozdamar, Ekinci, and Kucukyazici 2004), have been developed to help in various disaster scenarios and humanitarian relief efforts.

\section{Decision Support for Disaster Operations Management Using SD}

According to Galindo and Batta (2013), the SD method has been used in disaster operations management to facilitate the understanding of physical processes, flow of information, and emergency/crisis management decisions (Vlachos, Georgiadis, and Iakovou 2007). Focusing on natural hazards, Gillespie, Robards, and Cho (2004) analyzed safety requirements for designing systems with the SD method. Scholars also used SD to investigate evacuation, concentrating on the social and mental impacts on human behaviors (Simonovic and Ahmad 2005).

The SD method has been used to discuss many different specific humanitarian logistics issues ( $\mathrm{Hu}$ and Zhao 2011; Liu 2015; Ye and Liu 2014). Peng, Peng, and Chen (2014) modeled the process of providing victims with relief commodities after an earthquake. Goncalves (2011) developed an SD model to illustrate the tradeoffs between provision of relief assistance and capacity building in humanitarian relief organizations. Kunz, Reiner, and Gold (2014) compared different methods of disaster preparedness using SD.

\section{Theoretical Framework and Method}

Different stakeholders play important roles in logistics system design, planning, and operations. These decisionmakers face the added challenge of supporting collaborative decisions (Ortuño et al. 2013) with an expectation of a participatory approach (Bosch et al. 2013; Kapucu and Garayev 2011; Tatham and Christopher 2014).

Scholars have presented various participatory approaches. They take different forms and include: participatory rural appraisal (Chambers 1994) and participatory action research (Selener 1997). While these approaches have been widely accepted and promoted, most of them are designed to seek the best or optimal solution to a perceived problem (Mendoza and Prabhu 2006). In other words, they are viewed as problem-structuring tools more than problem-solving methods (Eden 1994). They are generally designed as tools to understand the problem rather than to aid decision or enable support (Forrester 2010).

SD is one of the methodologies applied to support stakeholder-based modeling processes (Lane 2010; Rouwette and Vennix 2010) that have a potentially powerful role in structuring stakeholder engagement, as 
confirmed in earlier studies (Stave 2010). SD offers a consistent and rigorous framework for identifying the scope of the problem, eliciting stakeholder views about root causes, system connections, and identifying policy levers.

In short, participatory SD modeling is more than simply eliciting knowledge about the problem from participants. It involves building shared ownership of the problem, system description, and solution seeking to achieve a common understanding and resolve (Stave 2010). In practical terms, it provides a mechanism for integrating scientific knowledge with local knowledge to build a shared mental model that solves a complex problem (Mendoza and Prabhu 2006).

As such, we proposed a framework based on participatory SD modeling that incorporates stakeholders into an otherwise purely analytic modeling process to support collaborative decision making (Antunes, Rui, and Videira 2006; Voinov and Gaddis 2008). In this model, decision-makers can analyze alternative policies and solutions by simulating experiments and real-world implementations.

The SD modeling process starts by building reference models (Sterman 2000), such as behavior-over-time graphs with notable variables. Cases/data on actual operations of humanitarian logistics being limited, as disasters are low probability events with specific characteristics, it was difficult to find data to conduct a simulation. We did, however, find a disaster exercise carried out by Shaanxi Province Emergency Management Office, which gave us enough related data collected from secondary sources to facilitate problem definition and model establishment. Our goal was to use this data to analyze actions in potential actual disaster response scenarios (Perry and Lindell 2003).

In the exercise, it is assumed that there is a post-seismic area in the southwest of Shaanxi province. The epicenter is located in a mountainous area with several disaster-affected counties surrounding it. The exercise was designed and executed according to Shaanxi Provincial Contingency Plans for Earthquake Response (Shaanxi Provincial Emergency Management Office 2014) and Shaanxi Provincial Contingency Plans for Natural Hazards Reliefs (Shaanxi Provincial Department of Civil Affairs 2017).

Although there is no special contingency plan for humanitarian logistics in Chinese emergency management system, a section entitled "Materials Support" is embedded in all contingency plans. According to the contingency plans intended for post-seismic contexts, the humanitarian logistics involve four task units. They include: Communication Support, Equipment Support, Transportation Support, and Road System Recovery, with a list of participants shown in Table 1.

Table 1: Participants Involved in Humanitarian Logistics Operations.

\begin{tabular}{|c|c|c|}
\hline \multirow[t]{2}{*}{ Task Unit } & \multicolumn{2}{|l|}{ Contingency Plan } \\
\hline & PCPE & PCPN \\
\hline Communication Support & EMO, STD, IID, PCP & $\mathrm{SB}, \mathrm{MB}, \mathrm{COA}$, \\
\hline Equipment Support & DRC, CAD, HD, DCC & HD, WSC, \\
\hline Transportation Support & PD, NSD, TD, NCA & TD, XRB, NCA, RTC \\
\hline Road system Recovery & UDD, WRD, PEP & WRD \\
\hline
\end{tabular}

See Appendix A and B for abbreviations and the list of agencies.

During disaster relief operations, supplies must be delivered from the local staging area in Xian City to a county-level staging area in the disaster-affected region (Kapucu, Lawther, and Pattison 2010). As such, a two-stage supply chain is established, as shown in Figure 1.

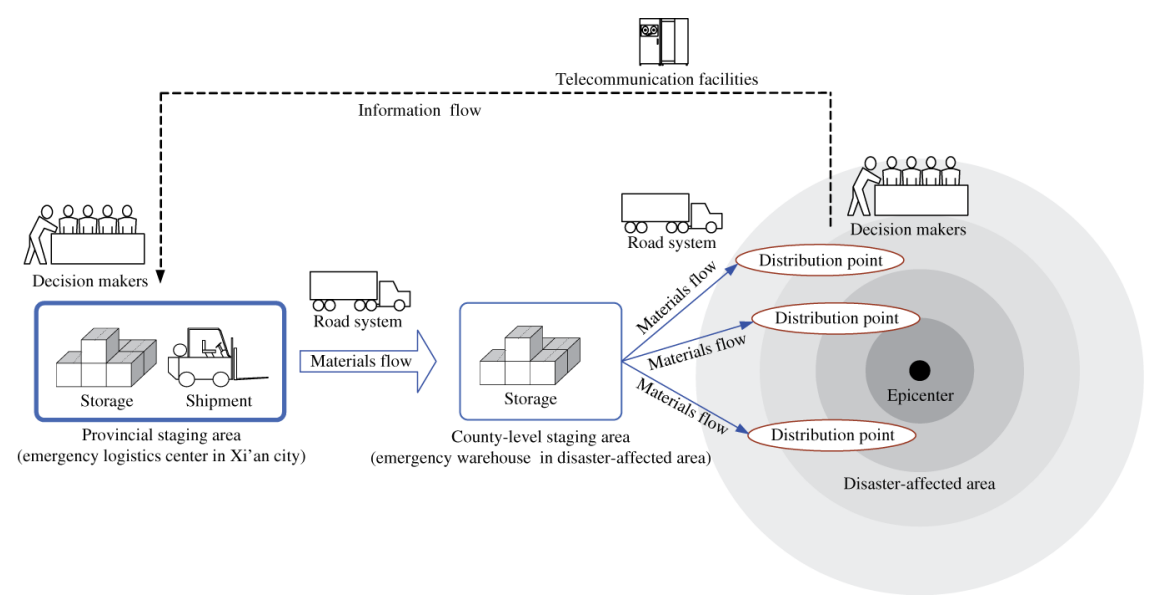


Figure 1: Humanitarian Logistics Operations in the Post-Seismic Context.

Methodologically, we conducted the research following four consecutive stages.

\section{Stage 1: Preparatory Stage}

Stakeholders involved in participatory SD modeling were determined according to the contingency plans assumed for post-seismic events (see Table 1). In the research, we surveyed representatives, including executive directors or managers, who were assumed to have the most accurate information about their organizations' activities and had the authority to make decisions dealing with disasters and humanitarian relief.

Since representatives are not the experts with specialized knowledge on SD, we also conducted interviews intended to explain the modeling process behind the study.

\section{Stage 2: System Definition Stage}

Group Modeling implies the active and direct involvement of stakeholders in model formulation and establishment. Hence, representatives not only provided input to the model, but also contributed to model specifications.

In this stage, we conducted participatory modeling processes in a series of workshops. According to the task units listed in Table 1, we held four workshops aided by SD simulation analysts.

1. Information and communication on problem definition.

Here, we described the expected function of task units and its representatives.

2. Eliciting participant ideas and opinions.

Here, we facilitated participant brainstorming about variables in the sub-model as it relates to each concerned task unit.

3. System and model definition.

Representatives were asked to work as a team to conclude model variables. Then, mental or cognitive maps, presented as a Casual Loop Diagram (Forrester 1961; Morecroft 2007), were generated (Mendoza and Prabhu 2006).

\section{Stage 3: Model Establishment and Validation}

Integrating the Casual Loop Diagram (CLD) created in each workshop, we generated the CLD on the entire humanitarian logistics operation. We generated Stock and Flow Diagram (SFD) and used Vensim DSS V5 (Ventana Systems 2003). All the representatives were invited to check the model to ensure structure and data accuracy.

\section{Stage 4: Simulation and Evaluation}

In this stage, participants discussed the indexes for performance evaluation and proposed other performance measurements for post-seismic contexts.

We then ran the simulation model and showed the results to all representatives. A discussion about performances in different scenarios followed.

Overall, insights were gained and integrated through iterative discussions with consensus reached, as shown in Figure 2 and Table 2.

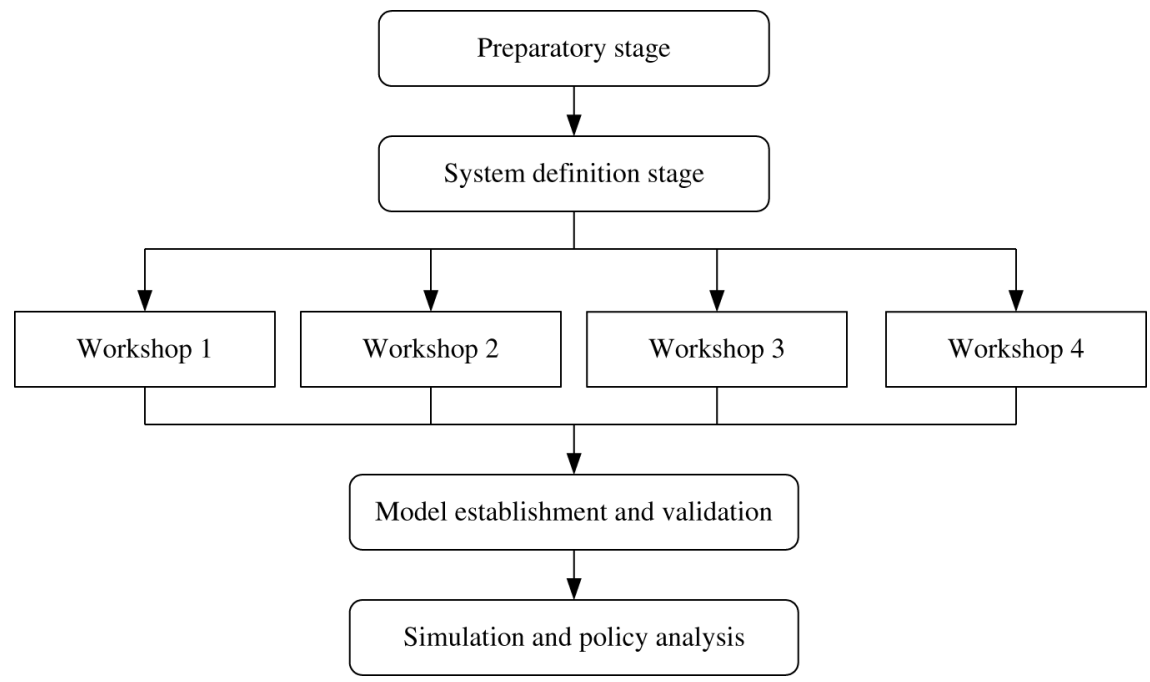


Figure 2: Participatory SD Modeling Process.

Table 2: Successive Stages in the Participatory SD Modeling Process.

\begin{tabular}{|c|c|c|c|}
\hline No. & Stage & Participants & Activities \\
\hline 1 & Preparatory Stage & All the Participants & $\begin{array}{l}\text { System Understanding and Problem } \\
\text { Definition }\end{array}$ \\
\hline \multirow[t]{23}{*}{2} & $\begin{array}{l}\text { System Definition } \\
\text { Stage }\end{array}$ & & System Definition \\
\hline & Workshop 1 & Shaanxi Provincial Emergency & System Analyses and Data Collection for \\
\hline & & Management Office & Communication Support \\
\hline & & Industry and Information Department & \\
\hline & & Seismological Bureau & \\
\hline & & Meteorological Bureau & \\
\hline & & Communications Administration & \\
\hline & & Party Committee Propaganda Department & \\
\hline & Workshop 2 & Development and Reform Commission & $\begin{array}{l}\text { System Analyses and Data Collection for } \\
\text { Materials Support }\end{array}$ \\
\hline & & Civil Affairs Department & \\
\hline & & Health Department & \\
\hline & & Water Supply Company & \\
\hline & & Disease Control Center & \\
\hline & Workshop 3 & Police Department & $\begin{array}{l}\text { System Analyses and Data Collection for } \\
\text { Transportation Support }\end{array}$ \\
\hline & & National Security Department & \\
\hline & & Transportation Department & \\
\hline & & Xi'an Railway Bureau & \\
\hline & & Northwest Civil Aviation Administration & \\
\hline & & Road Transportation Company & \\
\hline & Workshop 4 & UDD, WRD, PEP Urban-Rural & System Analyses and Data Collection for \\
\hline & & Development Department & Road System Recovery \\
\hline & & Water Resources Department & \\
\hline & & Provincial Electric Power Company & \\
\hline 3 & $\begin{array}{l}\text { Model Establishment } \\
\text { and Validation }\end{array}$ & All the Participants & $\begin{array}{l}\text { Model Establishment Based on Results of } \\
\text { Workshops }\end{array}$ \\
\hline 4 & Simulation and & All the Participants & Further Discussions to Reach Consensus \\
\hline & Policy Analysis & & Based on Simulation Results \\
\hline
\end{tabular}

\section{Simulation Design and Results}

\section{Simulation Design}

Through participatory SD modeling process, the model was established. See the CLD shown in Figure 3. 


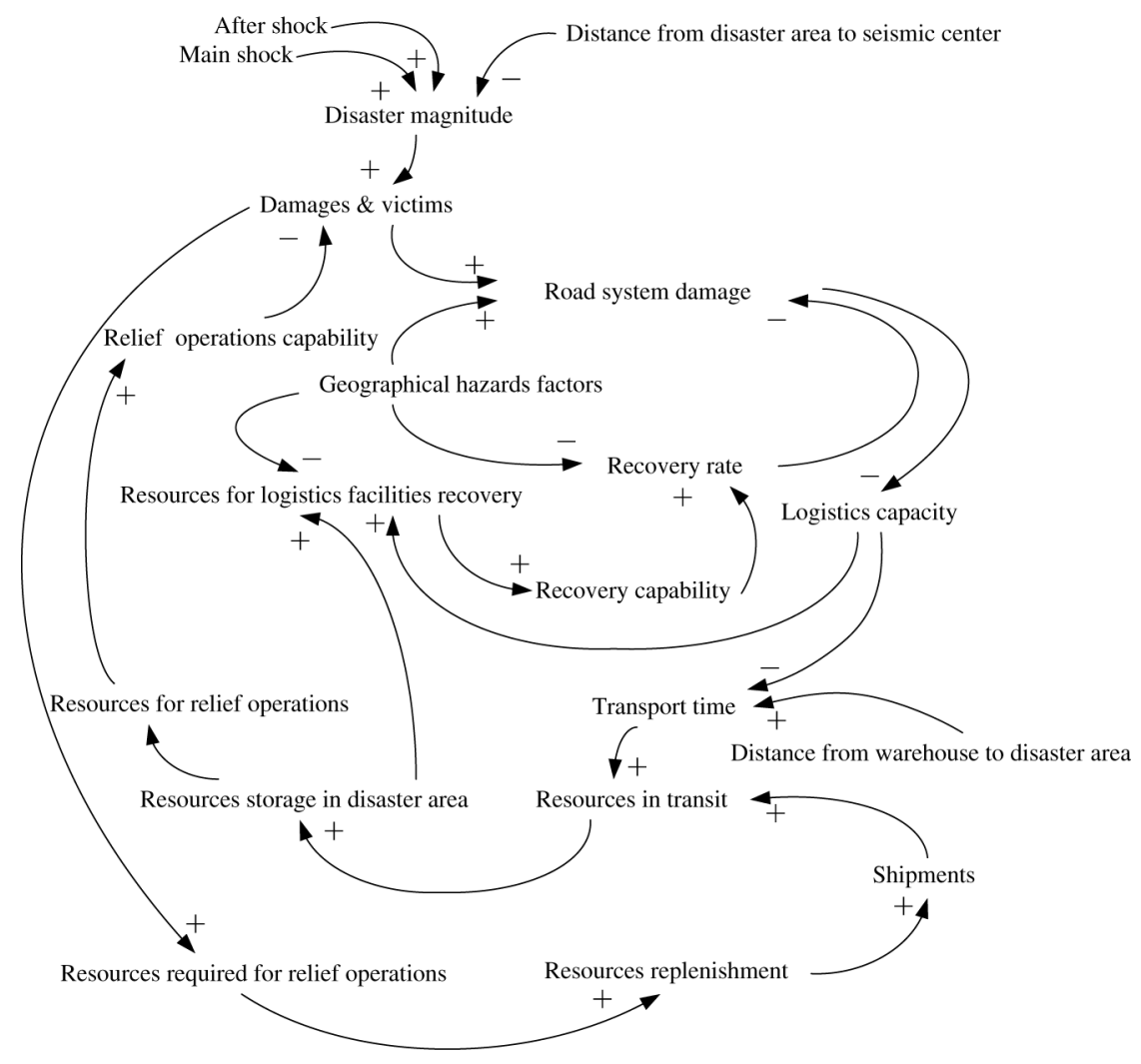

Figure 3: Casual Loop Diagram (CLD) of the SD Model.

Note: Notation of causal loop diagram can be seen in Appendix C.

We also presented the SFD on the simulation model based on CLD (see Figure 3), as shown in Figure 4.

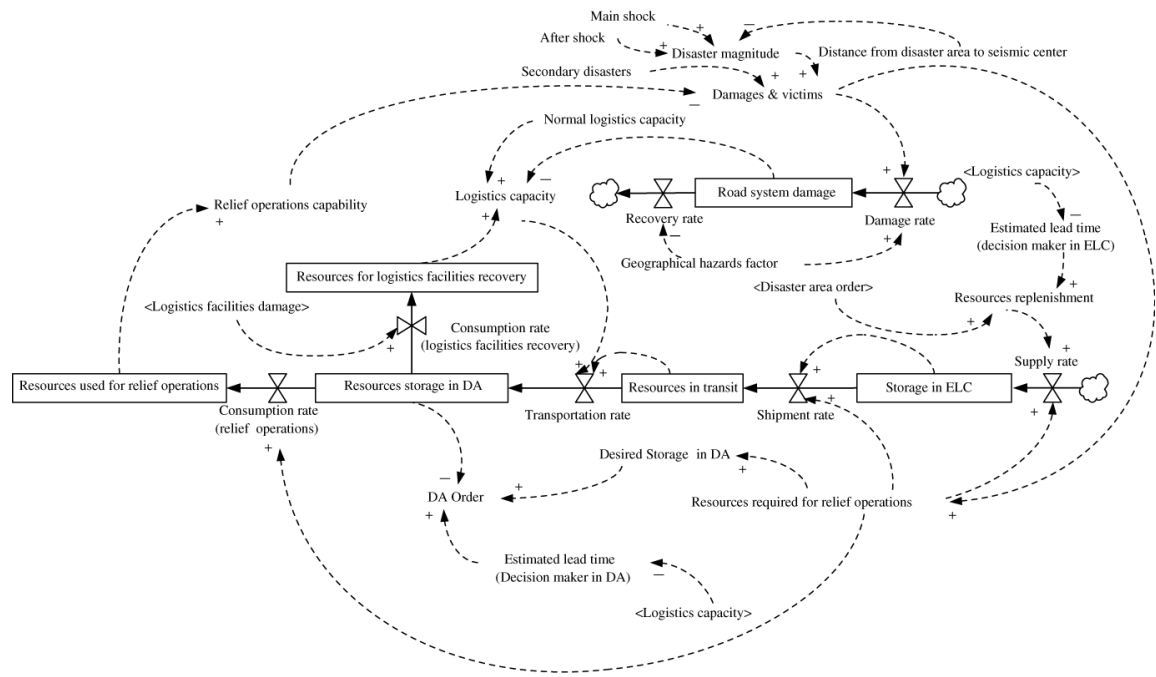

Figure 4: Stock and Flow Diagram (SFD) of the SD Model.

Subsequently, we highlighted some important factors and their feedback relationships as follows.

1. Road System Damage

In a post-seismic scenario, subsequent aftershocks and secondary disasters (e.g. landslides causing debris flow) increase the level of damage to road systems. These damages are accumulated and included as the stock variable "Road System Damage," which is reduced by continual attempts at repair.

In this model, we use the variable "Geographical Hazards Factor" to denote factors, such as mountains, which can trigger or aggravate dangers. These hazards, of course, decrease the efficiency of repair and recovery. Additionally, the greater the road capacity loss, the less the "Effective Repair Ability."

2. Transport Time 
Damage to the logistics system will cause longer transportation time. According to the method proposed by Bertini et al. (2005), we developed a function to describe the effects of road system conditions on transport time. This is shown in Equation (1), where $T_{t}$ is the transport time, $T_{N}$ is the normal transport time, $C_{t}$ is the current road capability in disaster, $M_{t}$ is the current volumes of supplies in transit, $T_{B}$ is the duration time of road blockage, and $C_{t}=0$ indicates road blockage.

$$
T_{t}=\left\{\begin{array}{c}
T_{B}, C_{t}=0 \\
T_{N}, M_{t} \leq C_{t} \\
T_{N} \times \frac{M_{t}}{C_{t}}, M_{t}>C_{t}
\end{array}\right.
$$

\section{Information Delay}

Information flow plays a key role in improving flow of resources and the success of humanitarian logistics (Najjar, Dahabiyeh, and Nawayseh 2018). In disaster-affected areas, delay information and communication flow occur when telecommunication facilities fail. Additionally, the received information is often inaccurate because of subjective speculation, rumors, noise and other errors. In this model, a negative exponential function is used to simulate the general trend of gradual decline, and a random variable is introduced to describe various noise factors.

\section{Decision Modes for Relief Goods Replenishment}

Two decision modes - Disaster Area Decision (DAD) and Emergency Logistics Center Decision (ELCD) are available for Relief Goods Replenishment. In DAD, a decision-maker in a disaster-affected area collects the information and is responsible for placing replenishment orders. As per the "order-up-to-S" ordering protocol, an order is submitted to replenish the inventory level to $S$ when said inventory level is below a preset stock level. In ELCD, the decision-maker in a emergency logistics center receives the information from the disaster-affected area and is responsible for placing replenishment orders. In the research, we assume that "order-up-to-S" is also implemented for inventory replenishment in emergency logistics centers.

Both of these decision modes have flaws in the post-seismic context, however. In terms of DAD, the decisionmakers know the exact amount of the current inventory and actual road conditions but cannot make precise lead time predictions due to information delays. In terms of ELCD, the decision-makers can make precise lead time predictions but usually lack exact information on inventory.

As a result, Joint Decision Mode (JDM) was proposed by participants as a third decision mode. According to JDM, both the orders from Disaster-affected Area (ODA) and orders from Emergency Logistics Center (OEL) are submitted and the final quantity of the replenishment decision is the mean of the two values. According to participants, the Replenishment Quantity of Relief Goods (RQRG) is calculated as the mean of Orders from Disaster-affected Area (ODA) and Orders from Emergency Logistics Center (OEL). See Equation (2).

$$
\mathrm{RQRG}=\frac{\mathrm{ODA}+\mathrm{OEL}}{2}
$$

\section{Results and Discussion}

Since logistics system performance should be customer-oriented and context specific (De Toni and Tonchia 2001; Stank, Keller, and Daugherty 2001), it's important to gauge the service level of humanitarian relief (Jeffers, Muhanna, and Nault 2008). Hence, we measured Satisfactory Rate of Demand (SRD), which is calculated as the value of Relief Goods Consumed divided by Demand. Efficiency factors, such as inventory holding costs, response time, and amount of supplies delivered to disaster affected area, are also used as performance metrics (Beamon and Balcik 2008; Lin Moe et al. 2007). We quantified another index, as well: Supply Rate (SR), which is the value of Relief Goods Delivered to Disaster Area divided by Relief Goods Prepared for Relief Operations. This measures effective utilization of relief goods.

According to Kapucu, Lawther, and Pattison (2010) and Peng, Peng, and Chen (2014), factors affecting performance of humanitarian logistics include: Distance from Epicenter, Geographical Hazards, Information Delay, and Decision Mode. Therefore, we established 36 scenarios using a cross-combination of these four factors to facilitate simulation design. The scenario definitions and simulation results are shown in Table 3. Scenarios 
1 and 2 were established according to the actual data collected from the exercise, while other scenarios were established as extensions of the exercise using simulation method.

Table 3: Scenario Definition and Simulation Results.

\begin{tabular}{|c|c|c|c|c|c|c|c|}
\hline \multicolumn{5}{|c|}{ Scenario Definition } & \multicolumn{3}{|c|}{ Simulation Results } \\
\hline \multirow[t]{2}{*}{ No. } & \multicolumn{3}{|c|}{ Environment Conditions } & \multirow{2}{*}{$\begin{array}{l}\text { Decision } \\
\text { Mode }\end{array}$} & \multirow{2}{*}{$\begin{array}{l}\text { Lead } \\
\text { Time }\end{array}$} & \multirow{2}{*}{$\begin{array}{r}\text { Satisfactory Rate } \\
\text { of Demand }\end{array}$} & \multirow{2}{*}{$\begin{array}{r}\text { Supply } \\
\text { Rate }\end{array}$} \\
\hline & $\begin{array}{l}\text { Distance from } \\
\text { Epicenter }\end{array}$ & $\begin{array}{l}\text { Geographical } \\
\text { Hazards }\end{array}$ & $\begin{array}{l}\text { Information } \\
\text { Delay }\end{array}$ & & & & \\
\hline 1 & $300 \mathrm{~km}$ & High & High & DAD & 61 days & 0.496 & 0.574 \\
\hline 2 & & & & ELCD & 52 days & 0.463 & 0.737 \\
\hline 3 & & & & JDM & 52 days & 0.482 & 0.689 \\
\hline 4 & & & Low & DAD & 59 days & 0.676 & 0.636 \\
\hline 5 & & & & ELCD & 50 days & 0.654 & 0.746 \\
\hline 6 & & & & JDM & 47 days & 0.674 & 0.712 \\
\hline 7 & & Low & High & DAD & 59 days & 0.513 & 0.657 \\
\hline 8 & & & & ELCD & 50 days & 0.502 & 0.748 \\
\hline 9 & & & & JDM & 49 days & 0.512 & 0.746 \\
\hline 10 & & & Low & DAD & 57 days & 0.714 & 0.682 \\
\hline 11 & & & & ELCD & 48 days & 0.702 & 0.796 \\
\hline 12 & & & & JDM & 45 days & 0.708 & 0.782 \\
\hline 13 & $200 \mathrm{~km}$ & High & High & DAD & 57 days & 0.674 & 0.614 \\
\hline 14 & & & & ELCD & 48 days & 0.609 & 0.789 \\
\hline 15 & & & & JDM & 43 days & 0.621 & 0.716 \\
\hline 16 & & & Low & DAD & 49 days & 0.676 & 0.639 \\
\hline 17 & & & & ELCD & 46 days & 0.654 & 0.678 \\
\hline 18 & & & & JDM & 46 days & 0.669 & 0.672 \\
\hline 19 & & Low & High & DAD & 55 days & 0.764 & 0.702 \\
\hline 20 & & & & ELCD & 45 days & 0.756 & 0.801 \\
\hline 21 & & & & JDM & 40 days & 0.763 & 0.782 \\
\hline 22 & & & Low & DAD & 47 days & 0.747 & 0.761 \\
\hline 23 & & & & ELCD & 44 days & 0.732 & 0.802 \\
\hline 24 & & & & JDM & 39 days & 0.741 & 0.802 \\
\hline 25 & $100 \mathrm{~km}$ & High & High & DAD & 53 days & 0.782 & 0.689 \\
\hline 26 & & & & ELCD & 42 days & 0.779 & 0.801 \\
\hline 27 & & & & JDM & 39 days & 0.781 & 0.799 \\
\hline 28 & & & Low & DAD & 44 days & 0.820 & 0.716 \\
\hline 29 & & & & ELCD & 41 days & 0.790 & 0.724 \\
\hline 30 & & & & JDM & 38 days & 0.819 & 0.722 \\
\hline 31 & & Low & High & DAD & 50 days & 0.831 & 0.749 \\
\hline 32 & & & & ELCD & 41 days & 0.812 & 0.816 \\
\hline 33 & & & & JDM & 32 days & 0.825 & 0.787 \\
\hline 34 & & & Low & DAD & 42 days & 0.913 & 0.798 \\
\hline 35 & & & & ELCD & 39 days & 0.847 & 0.827 \\
\hline 36 & & & & JDM & 30 days & 0.899 & 0.821 \\
\hline
\end{tabular}

According to the results shown in Table 3, all the solutions based on DAD achieve lower SR than those based on ELCD. And JDM achieves the least lead time. This suggests that solutions based on ELCD can result in less waste of relief goods, especially when information delay appears low. On the other hand, the solutions based on DAD achieve higher SRD than those based on ELCD. Thus, it can be concluded that DAD can achieve a higher service provision level in humanitarian operations than ELCD. It is important to achieve a balance between effective utilization of relief goods and service provision.

Since JDM was not tested in the actual exercise, we went further to compare it with DAD and ELCD in scenarios 1 and 2, which were established according to the actual data collected from the exercise. Considering the simulation results (shown in Figure 5), it can be concluded that JDM outperforms both DAD and ELCD, especially in the later stages of humanitarian logistics operations. This may be due to the repair and restoration of destroyed telecommunication infrastructure which would decrease information delay. 


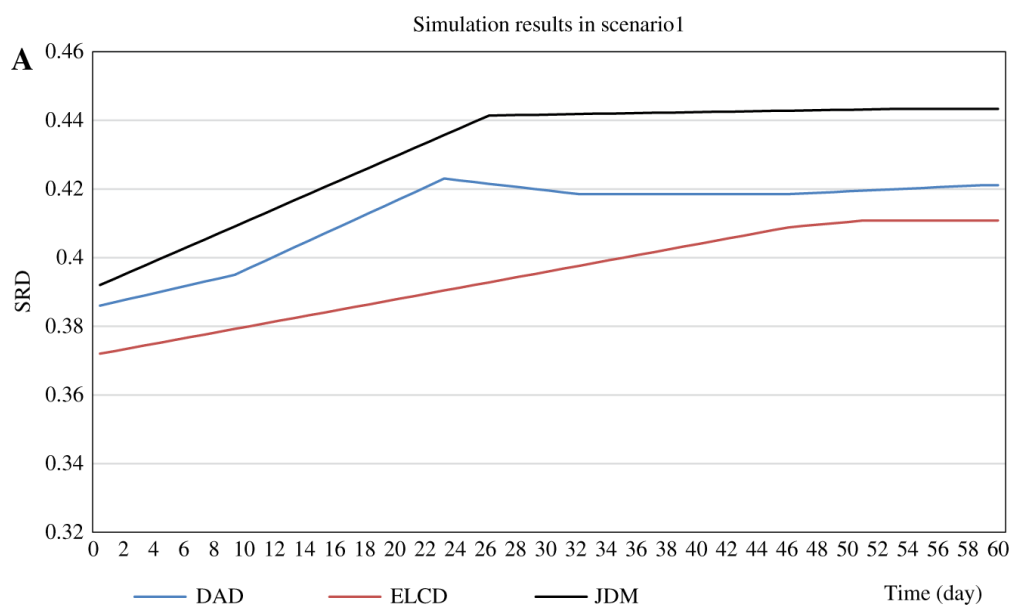

Simulation results in scenario 2

B

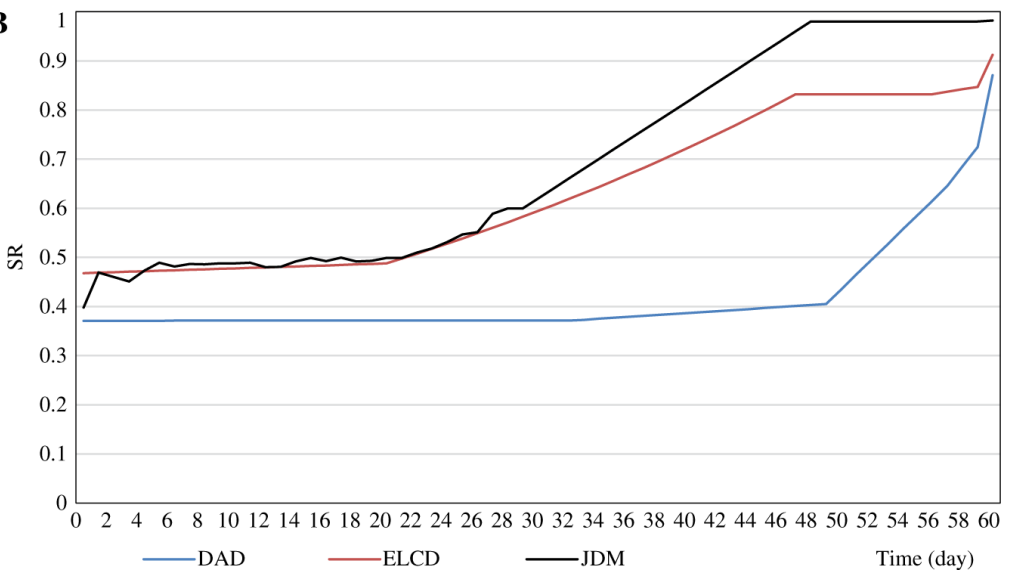

Figure 5: Simulation Results on Different Decision Modes.

(A) Simulation results in scenario 1. (B) Simulation results in scenario 2.

\section{Conclusion}

This research focuses on building an SD model that captures the complexity of humanitarian logistics systems and facilitates stakeholder engagement for efficient and effective humanitarian relief. Through participatory SD modeling process, in-depth information and knowledge about model development was collected. We also created different scenarios by which to analyze the performance of humanitarian logistics, and tested some solutions for improved performance.

Service level and effective utilization of humanitarian relief goods are two sides of a coin. Different decision modes achieve different levels of performance. Disaster Area Decision (DAD) can achieve a higher service level, while Emergency Logistics Center Decision (ELCD) can help relief goods be utilized more effectively. One of the most important problems is the balance between effective utilization of relief goods and service provision levels. According to the simulation results, Joint Decision Mode (JDM) not only outperforms both Disaster Area Decision (DAD) and Emergency Logistics Center Decision (ELCD), but also obtains a more balanced end result. On the other hand, Joint Decision Mode (JDM) is based on efficient information sharing, and depends on a reliable and integrated commanding platform.

Overall, this research suggests that applying SD is important and useful for humanitarian logistics planning. The model proposed in the research aims to facilitate collaborative decision-making, as it allows stakeholders to achieve system thinking and form shared mental models. Through analyses of different scenarios, involved stakeholders experience collaborative decision-making as a process. By comparing these different scenarios, which depend on internal and external factors, a holistic learning process for stakeholders is achieved. Thus, the research validates that a participatory SD modeling process can help accommodate opposing views/insights through scenario-specific simulations.

It should be said that the simulation model was based on participants' insights and knowledge which included some unconventional inventory management strategies (e.g. DAD and ELCD). This might limit the 
potential value of the study as it applies to real scenarios. It is recommended that this research be replicated from a supply chain perspective. For example, JDM could be revised, with RQRG-calculated data from both Disaster Area and Emergency Logistics Center, to measure more effective inventory management strategies.

This research also does not suggest that a full consensus on problems and solutions can be achieved through SD simulations, nor that an improved understanding of systems will translate into coordinated action. Only through stakeholder engagement in the participatory SD modeling process can increased ownership of problem scoping create consensus building and the formation of shared mental models. These are central to collaborative decision making. While we identified participants according to a variety of contingency plans, data was limited and the contingency plans may not cover all stakeholders (e.g. volunteer organizations) in potential disaster response. Content analysis and expert consultations can assist in addressing these limitations in the future.

\section{Funding}

This research was sponsored by National Social Science Fund of China (No. 16BZZ052). We also like to thank to anonymous reviewers for their suggestions.

\section{Appendix}

\section{A Emergency Plans}

\begin{tabular}{ll}
\hline Emergency Plan & Abbreviation \\
\hline PCPE & Shaanxi Provincial Contingency Plans for Earthquake Response \\
PCPN & Shaanxi Provincial Contingency Plans for Natural Hazards Reliefs \\
\hline
\end{tabular}

\section{B Departments/Agencies Common to the Plans}

\begin{tabular}{|c|c|}
\hline Abbreviation & Departments/Agencies \\
\hline EMO & Shaanxi Provincial Emergency Management Office \\
\hline DRC & Development and Reform Commission \\
\hline STD & Science and Technology Department \\
\hline IID & Industry and Information Department \\
\hline PD & Police Department \\
\hline NSD & National Security Department \\
\hline CAD & Civil Affairs Department \\
\hline UDD & Urban-Rural Development Department \\
\hline $\mathrm{TD}$ & Transportation Department \\
\hline WRD & Water Resources Department \\
\hline HD & Health Department \\
\hline SB & Seismological Bureau \\
\hline MB & Meteorological Bureau \\
\hline PEP & Provincial Electric Power Company \\
\hline XRB & Xi'an Railway Bureau \\
\hline $\mathrm{COA}$ & Communications Administration \\
\hline WSC & Water Supply Company \\
\hline DCC & Disease Control Center \\
\hline NCA & Northwest Civil Aviation Administration \\
\hline PCP & Party Committee Propaganda Department \\
\hline RTC & Road Transportation Company \\
\hline
\end{tabular}

\section{Notation of Causal Loop Diagram (CLDs)}

Source: Adapted from Sterman (2000). 
CLDs are conceptual tools to represent the causal chain of effects between a set of variables characterizing a dynamic issue. Arrows are used in CLDs to represent causal links between variables. A positive link (+) indicates that, all else equal, variables change in the same direction (e.g. if "Variable A" is causally linked to "Variable B," when A increases then B also increases). A negative link (-) expresses that the connected variables change in opposite directions.

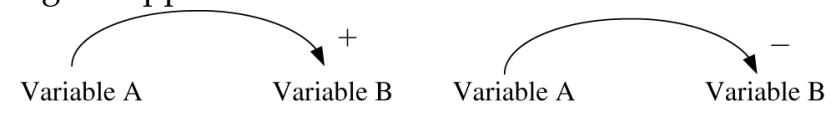

Positive causal link Negative causal link

Two types of feedback loops may be created around two or more variables. These are classified as: reinforcing loops (also called positive feedback loops), when tracing the effect of a change around the loop reinforces the initial change; balancing loops (also called negative feedback loops), when the effect of a change in any of the variables around the loop opposes the initial change. Balancing loops characterize self-correcting or stabilizing behavior, while reinforcing loops are sources of growth, erosion and collapse in systems.

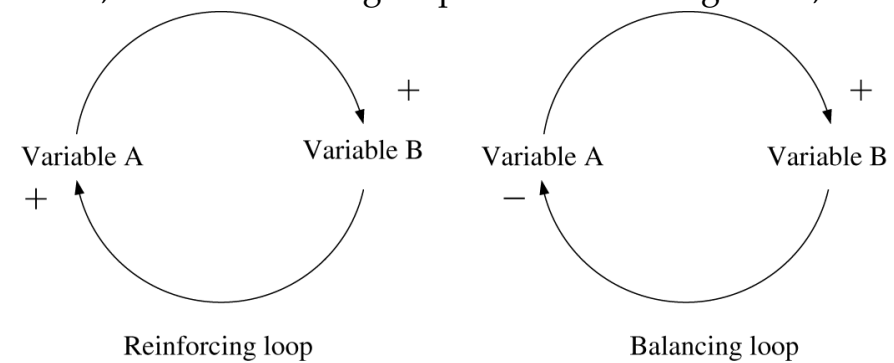

\section{References}

Antunes, P., S. Rui, and N. Videira. 2006. "Participatory Decision Making for Sustainable Development-the Use of Mediated Modelling Techniques." Land Use Policy 23 (1): 44-52.

Barbarosoğlu, G., L. Özdamar, and A. Cevik. 2002. “An Interactive Approach for Hierarchical Analysis of Helicopter Logistics in Disaster Relief Operations." European Journal of Operational Research 140 (1): 118-133.

Beamon, B. M., and B. Balcik. 2008. “Performance Measurement in Humanitarian Relief Chains.” International Journal of Public Sector Management 21 (1): 4-25.

Berariu, R., C. Fikar, M. Gronalt, and P. Hirsch. 2016. “Training Decision-Makers in Flood Response with System Dynamics." Disaster Prevention \& Management 25 (2): 118-136.

Bertini, R. L., S. Hansen, A. Byrd, and T. Yin. 2005. “Experience Implementing a User Service for Archived Intelligent Transportation Systems Data." Transportation Research Record Journal of the Transportation Research Board 16 (1): 90-99.

Bigley, G. A., and K. H. Roberts. 2001. “The Incident Command System: High Reliability Organizations for Complex and Volatile Task Environments." Academy of Management Journal 44 (6): 1281-1299.

Blackstock, K. L., G. J. Kelly, and B. L. Horsey. 2007. “Developing and Applying a Framework to Evaluate Participatory Research for Sustainability." Ecological Economics 60 (4): 726-742.

Bosch, O. J. H., N. C. Nguyen, T. Maeno, and T. Yasui. 2013. "Managing Complex Issues Through Evolutionary Learning Laboratories." Systems Research and Behavioral Science 30 (2): 116-135.

Buchanan, L., and A. O'Connell. 2006. “A Brief History of Decision-Making.” Harvard Business Review 84 (1): 32-41.

Chambers, R. 1994. “Participatory Rural Appraisal: Challenges, Potentials and Paradigm.” World Development 22 (10): $1437-1454$.

Cosgrave, J. 1996. "Decision Making in Emergencies." Disaster Prevention and Management 5 (4): 28-35.

Cozzolino, A. 2010. "Humanitarian Logistics." Development in Practice 20 (2): 305-307.

De Toni, A., and S. Tonchia. 2001. "Performance Measurement Systems-Models, Characteristics and Measures." International Journal of Operations \& Production Management 21 (1/2): 46-71.

Eden, C. 1994. “Cognitive Mapping and Problem Structuring for System Dynamics Model Building.” System Dynamics Review 10 (2-3): 20.

Ergonul, S. 2005. "A Probabilistic Approach for Earthquake Loss Estimation." Structural Safety 27 (4): 309-321.

Flin, R. 2001. "Decision Making in Crises: The Piper Alpha Disaster," in Managing Crises: Threats, Dilemmas, Opportunities, edited by U. Rosenthal, A. R. Boin, and L. Comfort, 103-118. Springfield, IL: Charles C. Thomas.

Flueler, T. 2006. Decision-Making for Complex Socio-Technical Systems: Robustness from Lessons Learned in Long-term Radioactive Waste Governance, Dordrecht, The Netherlands: Springer.

Forrester, J. W. 1961. Industrial Dynamics. Cambridge, MA: MIT Press.

Forrester, J. W. 2010. “System Dynamics, Systems Thinking, and Soft OR.” System Dynamics Review 10 (2-3): 245-256.

Galindo, G., and R. Batta. 2013. "Review of Recent Developments in OR/MS Research in Disaster Operations Management." European Journal of Operational Research 230 (2): 201-211.

Garrido, R. A., P. Lamas, and F. J. Pino. 2015. “A Stochastic Programming Approach for Floods Emergency Logistics.” Transportation Research Part E 75: 18-31. 
Chaffarzadegan, N., J. Lyneis, and G. P. Richardson. 2011. “How Small System Dynamics Models can Help the Public Policy Process." System Dynamics Review 27 (1): 22-44.

Gillespie, D. F., K. J. Robards, and S. Cho. 2004. “Designing Safe Systems: Using System Dynamics to Understand Complexity.” Natural Hazards Review 5 (2): 82-88.

Concalves, P. 2011. "Balancing Provision of Relief and Recovery with Capacity Building in Humanitarian Operations." Operations Management Research 4 (1-2): 39-50.

Holguín-Veras, J., E. Taniguchi, M. Jaller, F. Aros-Vera, F. Ferreira, and R. G. Thompson. 2014. “The Tohoku Disasters: Chief Lessons Concerning the Post Disaster Humanitarian Logistics Response and Policy Implications." Transportation Research Part A Policy \& Practice 69: 86104.

Hu, J., and L. Zhao. 2011. "Emergency Logistics Strategy in Response to Anthrax Attacks Based on System Dynamics." International Journal of Mathematics in Operational Research 3 (5): 490-509.

Hwang, H. S. 1999. “A Food Distribution Model for Famine Relief.” Computers \& Industrial Engineering 37 (1-2): 335-338.

Jeong, K. Y., J. D. Hong, and Y. Xie. 2014. “Design of Emergency Logistics Networks, Taking Efficiency, Risk and Robustness into Consideration." International Journal of Logistics 17 (1): 1-22.

Jeffers, P. I., W. A. Muhanna, and B. R. Nault. 2008. “Information Technology and Process Performance: An Empirical Investigation of the Interaction between IT and non-IT Resources." Decision Sciences 39 (4): 703-735.

Johnston, J. H., J. E. Driskell, and E. Salas. 1997. "Vigilant and Hypervigilant Decision Making." Journal of Applied Psychology 82 (4): 614-622.

Kapucu, N., and V. Garayev. 2011. "Collaborative Decision-Making in Emergency and Disaster Management." International Journal of Public Administration 34 (6): 366-375.

Kapucu, N., W. C. Lawther, and S. Pattison. 2010. "Logistics and Staging Areas in Managing Disasters and Emergencies." Journal of Homeland Security \& Emergency Management 4 (2): 425-426.

Kaynak, R., and A. T. Tuğer. 2014. "Coordination and Collaboration Functions of Disaster Coordination Centers for Humanitarian Logistics." Procedia - Social and Behavioral Sciences 109 (2): 432-437.

Kunz, N., G. Reiner, and S. Cold. 2014. "Investing in Disaster Management Capabilities Versus Pre-Positioning Inventory: A New Approach to Disaster Preparedness." International Journal of Production Economics 157: 261-272.

Lane, D. C. 2010. "Participative Modelling and Big Issues: Defining Features of System Dynamics?” Systems Research \& Behavioral Science 27 (4): 461-465.

Li, L., and S. Tang. 2008. "An Artificial Emergency-Logistics-Planning System for Severe Disasters." IEEE Intelligent Systems 23 (4): 86-88.

Lin Moe, T., F. Gehbauer, S. Senitz, and M. Mueller. 2007. "Balanced Scorecard for Natural Disaster Management Projects." Disaster Prevention and Management 16 (5): 785-806.

Liu, A. 2015. “Research on Resilience of Emergency Logistics Network Responding to Public Health Emergencies Based on System Dynamics." Journal of Information \& Computational Science 12 (3): 1001-1010.

Long, D. C., and D. F. Wood. 1995. “The Logistics of Famine Relief.” Journal of Business Logistics 16 (1): 213-229.

Mendoza, G. A., and R. Prabhu. 2006. "Participatory Modeling and Analysis for Sustainable Forest Management: Overview of Soft System Dynamics Models and Applications." Forest Policy \& Economics 9 (2): 179-196.

Morecroft, ]. 2007. Strategic Modelling and Business Dynamics - A Feedback Systems Approach. West Sussex: John Wiley \& Sons Ltd.

Murray, S. 2005 (January) 7. “How to Deliver on the Promises? Supply Chain Logistics: Humanitarian Agencies are Learning Lessons from Business in Bringing Essential Supplies to Regions Hit by the Tsunami." Financial Times9.

Najjar, M. S., L. Dahabiyeh, and M. Nawayseh. 2018. "Share if you Care: The Impact of Information Sharing and Information Quality on Humanitarian Supply Chain Performance - a Social Capital Perspective." Information Development doi: 10.1177/02666666918755427 (Ahead of Print).

Ortuño, M. T., P. Cristóbal, J. M. Ferrer, F. J. Martín-Campo, S. Muñoz, G. Tirado, and B. Vitoriano. 2013. “Decision Aid Models and Systems for Humanitarian Logistics. A Survey." Atlantis Computational Intelligence Systems 7: 17-44.

Ozdamar, L., E. Ekinci, and B. Kucukyazici. 2004. “Emergency Logistics Planning in Natural Disasters.” Annals of Operations Research 129 (1-4): 217-245.

Peng, M., Y. Peng, and H. Chen. 2014. “Post-Seismic Supply Chain Risk Management: A System Dynamics Disruption Analysis Approach for Inventory and Logistics Planning." Computers \& Operations Research 42: 14-24.

Perry, R. W., and M. K. Lindell. 2003. "Preparedness for Emergency Response: Guidelines for the Emergency Planning Process." Disasters 27 (4): $336-350$

Rouwette, E. A. J. A., and ]. A. M. Vennix. 2010. “System Dynamics and Organizational Interventions.” Systems Research \& Behavioral Science 23 (4): 451-466.

Selener, D. 1997. Participatory Action Research and Social Change, New York: The Cornell Participatory Action Research Network Cornell University.

Sellnow, T. L., M. W. Seeger, and R. R. Ulmer. 2002. “Chaos Theory, Informational Needs, and Natural Disasters.” Journal of Applied Communication Research 30 (4): 269-292.

Shaanxi Provincial Emergency Management Office. Shaanxi Provincial Contingency Plans for Earthquake Response 2014. Retrieved November, 2017. from http://www.shaanxi.gov.cn.

Shaanxi Provincial Department of Civil Affairs. Shaanxi Provincial Contingency Plans for Natural Hazards Reliefs 2017. Retrieved November, 2017. from http://shaanxi.mca.gov.cn/article/zcfg/jzjj/201701/20170101000145.shtml.

Sheu, J. B. 2007. “An Emergency Logistics Distribution Approach for Quick Response to Urgent Relief Demand in Disasters." Transportation Research Part E 43 (6): 687-709.

Simonovic, S. P., and S. Ahmad. 2005. “Computer-Based Model for Flood Evacuation Emergency Planning." Natural Hazards 34 (1): 25-51.

Smith, W., and J. Dowell. 2000. "A Case Study of Coordinative Decision-Making in Disaster Management." Ergonomics 43 (8): 1153-1166.

Stank, T. P., S. B. Keller, and P. J. Daugherty. 2001. "Supply Chain Collaboration and Logistical Service Performance." Journal of Business Logistics 22 (1): 29-48. 
Stave, K. 2010. "Participatory System Dynamics Modeling for Sustainable Environmental Management: Observations from Four Cases." Sustainability 2 (9): 2762-2784.

Sterman, J. D. 2000. Business Dynamics - Systems Thinking and Modeling for a Complex World. Boston: McCraw-Hill.

Tatham, P., and M. Christopher. 2014. Humanitarian Logistics - Meeting the Challenge of Preparing for and Responding to Disasters, London and Philadelphia, PA: Kogan Page.

Thayaparan, M., M. Siriwardena, C. I. Malalgoda, D. Amaratunga, I. Lill, and A. Kaklauskas. 2015. “Enhancing Post-Disaster Reconstruction Capacity through Lifelong Learning in Higher Education." Disaster Prevention and Management 24 (3): 338-354.

Useem, M., J. R. Cook, and L. Sutton. 2005. “Developing Leaders for Decision Making Under Stress: Wildland Firefighters in the South Canyon Fire and its Aftermath." Academy of Management Learning \& Education 4 (4): 461-485.

Van Wassenhove, L. N. 2006. "Blackett Memorial Lecture. Humanitarian Aid Logistics: Supply Chain Management in High Cear." Journal of the Operational Research Society 57 (5): 475-489.

Ventana Systems. 2003. Vensim 5 Modeling Guide. Retrieved on January 23, 2018 from http://kurser.math.su.se/pluginfile.php/23750/mod_folder/content/o/ModelingGuide.pdf?forcedownload=1.

Vlachos, D., P. Georgiadis, and E. lakovou. 2007. "A System Dynamics Model for Dynamic Capacity Planning of Remanufacturing in ClosedLoop Supply Chains." Computers \& Operations Research 34 (2): 367-394.

Voinov, A., and E. J. B. Gaddis. 2008. "Lessons for Successful Participatory Watershed Modeling: A Perspective from Modeling Practitioners." Ecological Modelling 216 (2): 197-207.

Wang, L., J. Song, and L. Shi. 2015. “Dynamic Emergency Logistics Planning: Models and Heuristic Algorithm.” Optimization Letters 9 (8): $1533-1552$.

World Bank. Building Regulation for Resilience: Managing Risks for Safer Cities 2015. Retrieved on January 23, 2018. from http://documents.worldbank.org/curated/en/326581468337788007/Building-regulation-for-resilience-managing-risks-for-safer-cities.

Ye, Y., and N. Liu. 2014. "Humanitarian Logistics Planning for Natural Disaster Response with Bayesian Information Updates." Journal of Industrial \& Management Optimization 10 (3): 665-689.

Zhao, J., and C. Cao. 2015. “Review of Relief Demand Forecasting Problem in Emergency Logistic System." Journal of Service Science \& Management 8 (1): 92-98. 